\title{
Age at Menarche, Menstrual Characteristics, and Risk of Preeclampsia
}

\author{
Dejene F. Abetew, ${ }^{1}$ Daniel A. Enquobahrie, ${ }^{1,2}$ Michal Dishi, ${ }^{1}$ Carole B. Rudra, ${ }^{3}$ \\ Raymond S. Miller, ${ }^{1}$ and Michelle A. Williams ${ }^{1,2}$ \\ ${ }^{1}$ Center for Perinatal Studies, Swedish Medical Center, Seattle, WA 98104, USA \\ ${ }^{2}$ Department of Epidemiology, University of Washington, Seattle, WA 98195, USA \\ ${ }^{3}$ Department of Social and Preventive Medicine, The State University of New York at Buffalo, Buffalo, NY 14214-8001, USA
}

Correspondence should be addressed to Dejene F. Abetew, dejene.abetew@swedish.org

Received 3 October 2011; Accepted 14 November 2011

Academic Editors: S. Hansson, R. Kimmig, and T. Perez-Medina

Copyright ( 2011 Dejene F. Abetew et al. This is an open access article distributed under the Creative Commons Attribution License, which permits unrestricted use, distribution, and reproduction in any medium, provided the original work is properly cited.

\begin{abstract}
We examined associations of age at menarche and menstrual characteristics with the risk of preeclampsia among participants $(n=3,365)$ of a pregnancy cohort study. Data were collected using in-person interviews and medical record abstraction. Logistic regression was used to estimate adjusted odds ratio (OR) and $95 \%$ confidence interval (95\% CI). There was a significant inverse association between age at menarche and risk of preeclampsia ( $P$ value for trend $<0.05)$. Association of long cycle length $(>36$ days) with higher risk of preeclampsia was present only among women who had prepregnancy body mass index $<25 \mathrm{~kg} / \mathrm{m}^{2}$ (interaction $P$ value $=0.04)$. Early menarche is associated with higher risk of preeclampsia. Prepregnancy weight may modify associations of long menstrual cycles with risk of preeclampsia.
\end{abstract}

\section{Introduction}

Menarche, an important milestone of sexual development, signals the end of puberty and the beginning of reproductive life in females $[1,2]$. Both early and delayed menarche have been associated with increased cardiovascular disease (CVD) risk factors (including metabolic syndrome) and disease in adolescent girls and young women [1,3-7]. Further more, women with long and irregular menstrual cycles have been shown to have higher risk for CVD and type 2 diabetes $[5,7,8]$.

Preeclampsia, a multisystem pregnancy disorder, is characterized by hypertension and proteinuria that develop after 20 weeks of gestation [9-14]. The precise pathophysiologic mechanisms of preeclampsia remain unknown and are subjects of extensive research [9-12, 15-20]. Since previously identified risk factors of preeclampsia (including maternal obesity, insulin resistance, and other hormonal factors) [15, 18 ] are potentially associated with early menarche, delayed menarche and/or menstrual irregularities $[4,5]$, age at menarche, and menstrual characteristics may be associated with risk of preeclampsia. Previous reports on associations of menstrual characteristics with preeclampsia were based on case-control studies [5]. Among a well-characterized pregnancy cohort, we investigated relationships between age at menarche and menstrual characteristics with risk of preeclampsia. We also examined whether prepregnancy body mass index (BMI), adult weight gain, or maternal birth weight, a marker of intrauterine development that has been related to reproductive outcomes [21-24], modified these associations.

\section{Methods}

2.1. Study Population. Study participants were drawn from participants of the Omega study $[9,25]$. Briefly, the study population comprised of women attending prenatal care clinics affiliated with Swedish Medical Center (SMC) in Seattle, WA, and Tacoma General Hospital (TGH) in Tacoma, WA. Women were eligible if they initiated prenatal care before 20 weeks of pregnancy, were $>18$ years old, 
were able to speak and read English, plan to carry the pregnancy to term, or planned to deliver at either of the two research hospitals. During 1996-2008, 5,063 eligible women were approached and 4,000 (79\%) participants were enrolled in the study. Of these, participants who moved or delivered elsewhere $(n=151)$, delivered before 20 weeks $(n=43)$, had prior chronic hypertension $(n=$ $167)$, and had no available information on menstrual age $(n=274)$ or menstrual characteristics were excluded from current analyses $(n=3,365)$. Study protocols were approved by the Institutional Review Boards of SMC and TGH. All participants provided written informed consent.

2.2. Data Collection. Using standardized questionnaires administered by a trained interviewer at or near the time of enrollment, we gathered information on age at menarche, menstrual characteristics, and other covariates including maternal sociodemographic factors, medical/reproductive histories, prepregnancy BMI, adult weight gain (differences in weight at age 18 and prepregnancy weight), and maternal birth weight. After delivery, maternal and infant medical records were reviewed for information on the course and outcomes of pregnancy.

Preeclampsia was defined using American College of Obstetricians and Gynecologists (ACOG) guidelines [26] as sustained pregnancy-induced hypertension with proteinuria. Hypertension was defined as sustained elevated blood pressure $(\mathrm{BP})$ readings of $140 / 90 \mathrm{~mm} \mathrm{Hg}$ (with readings taking place 6 hours apart) after 20 weeks of gestation. Proteinuria was defined as protein concentration of $\geq 30 \mathrm{mg} / \mathrm{dL}$ on $\geq 2$ random urine specimen collected 4 hours apart.

We gathered information on menstrual cycle characteristics including (a) age at menarche (the interviewer asked "At what age did you have your first period?"), (b) irregular menses after menarche (the interviewer asked "During the first year after starting your menstrual periods, did your periods become regular? That is, could you predict within one week when your next menstrual period would begin?" and "Have your period ever been regular without using birth control pills, injection, or implants?"), and (c) usual cycle length (the interviewer asked "On average, how often did you have your menstrual period? That is, how many days were there between the first day of one menstrual period and the first day of the next?").

2.3. Statistical Analysis. We examined general characteristics of the study population using mean (standard deviation) for continuous variables and numbers (\%) for categorical variables. We used unadjusted and multivariable adjusted logistic regression analyses to compute odds ratio (OR) and $95 \%$ confidence interval (95\% CI). We used a priori identified indicator variables to categorize age at menarche $(\leq 11,1213,14$, and $\geq 15$ years $)$ and cycle length $(\leq 24,25-$ $30,31-35$, and $\geq 36$ days) [5]. Categories of age 13 years and 25-30 days were used as references for age at menarche and cycle length categories, respectively. Potential confounders that resulted in $>10 \%$ difference in estimated ORs (com- paring unadjusted and adjusted regression coefficients) were considered as confounders and were retained in multivariable models. The first adjusted model included variables for maternal age, race/ethnicity, parity, maternal birth weight, and pregestational diabetes. The second adjusted model included variables for prepregnancy BMI in addition to variables included in Model 1. We also evaluated potential effect modification of the relationship between early age at menarche and menstrual cycle length with preeclampsia risk by prepregnancy overweight/obesity status (BMI $\geq$ $25 \mathrm{~kg} / \mathrm{m}^{2}$ ), adult weight gain, and maternal birth weight. For these analyses, we defined early menarche as age at menarche $\leq 11$ years and long menstrual length as menstrual cycle $\geq 36$ days. We used both interaction terms and stratified analyses to evaluate the presence of effect modification [27]. All analyses were conducted using SPSS version 14. Statistical significance was defined as two-sided $P<0.05$.

\section{Results}

Participants, 32.6 years old on average, were predominantly white $(86.4 \%)$ (Table 1). Among 3,365 participants of the cohort, $80(2.4 \%)$ developed preeclampsia. We observed a statistically nonsignificant higher risk of preeclampsia (unadjusted OR: 1.56, 95\% CI: 0.76-3.19) among participants with long cycle length ( $\geq 36$ days) compared with participants with normal cycle length (25-30 days) (Table 2). However, this relationship was not present after adjustment for confounders. We did not find associations of irregular menses with risk of preeclampsia. There was a significant inverse association between age at menarche and risk of preeclampsia $(P$ value for trend $<0.05)$ (Table 2$)$. While the increased risk of preeclampsia associated with age at menarche $\leq 11$ years, compared with the referent (age 13), did not reach statistical significance, women who had menarche at $\leq 10$ years of age $(n=8$ preeclampsia cases and $n=106$ controls) had a 3 -fold increase in risk of preeclampsia compared with women who had menarche at age 13 years (adjusted OR: 2.99, 95\% CI 1.24-7.21) (not shown).

In effect modification analyses, we observed significant interaction between prepregnancy BMI and cycle length $(P$ value for interaction $=0.04)$ (Table 3$)$. The association between longer cycle length and higher risk of preeclampsia was present only among women who had prepregnancy BMI < $25 \mathrm{~kg} / \mathrm{m}^{2}$ (OR: 2.56, 95\% CI: 1.12-5.88) but not among women who had prepregnancy BMI $\geq 25 \mathrm{~kg} / \mathrm{m}^{2}$ (OR: $0.44,95 \%$ CI: $0.10-1.84)$. The association between early age at menarche ( $\leq 11$ years) and risk of preeclampsia was significantly higher and statistically significant among women who had birth weight $\geq 2.5 \mathrm{~kg}$ (OR: 3.57, 95\% CI: 1.07-11.93) compared with the association among women who had birth weight $<2.5 \mathrm{~kg}$ (OR: 1.20 , 95\% CI: $0.45-$ 3.18 ), although the interaction term was not statistically significant $(P$ value $>0.05)$. Women who were overweight and had early menarche ( $\leq 11$ years) had a 4 -fold increase in risk of preeclampsia compared with women who were not overweight and had menarche after age 11 (95\% CI: 
TABLE 1: Age at menarche and selected characteristics of the study population.

\begin{tabular}{|c|c|c|c|c|c|c|}
\hline \multirow{2}{*}{ Characteristics } & \multirow{2}{*}{$\begin{array}{l}\text { Entire cohort } \\
\quad(n=3365)\end{array}$} & \multicolumn{5}{|c|}{ Age of menarche (years) } \\
\hline & & $\leq 11(n=487)$ & $12(n=881)$ & $13(n=1048)$ & $14(n=493)$ & $\geq 15(n=456)$ \\
\hline Maternal age, years ${ }^{\mathrm{a}}$ & $32.6 \pm 4.5$ & $31.9 \pm 4.9$ & $32.6 \pm 4.5$ & $32.6 \pm 4.2$ & $32.7 \pm 4.3$ & $33.1 \pm 4.2$ \\
\hline$<20$ & $20(0.6)$ & $9(1.8)$ & $1(0.1)$ & $6(0.6)$ & $2(0.4)$ & $2(0.4)$ \\
\hline $20-34$ & $2229(66.2)$ & $333(68.4)$ & $587(66.6)$ & $706(67.4)$ & $329(66.7)$ & $274(60.1)$ \\
\hline $35+$ & $1116(33.2)$ & $145(29.8)$ & $293(33.3)$ & $336(32.1)$ & $162(32.9)$ & $180(39.5)$ \\
\hline Maternal White race & $2909(86.4)$ & $380(78)$ & $752(85.4)$ & $922(88)$ & $447(90.7)$ & $408(89.5)$ \\
\hline Post-high-school education & $3237(96.2)$ & $457(93.8)$ & $843(95.7)$ & $1016(96.9)$ & $478(97)$ & $443(97.1)$ \\
\hline Nulliparous & $2138(63.5)$ & $309(63.4)$ & $559(63.5)$ & $686(65.5)$ & $301(61.1)$ & $283(62.1)$ \\
\hline Smoked during pregnancy & $200(5.9)$ & $38(7.8)$ & $52(5.9)$ & $53(5.1)$ & $28(5.7)$ & $29(6.4)$ \\
\hline Prepregnancy BMI, kg/m ${ }^{2 \mathrm{a}}$ & $23.4 \pm 4.7$ & $25.3 \pm 5.9$ & $23.9 \pm 4.9$ & $22.9 \pm 4.1$ & $22.4 \pm 3.8$ & $22.3 \pm 3.9$ \\
\hline$<18.5$ & $147(4.4)$ & $6(1.2)$ & $30(3.4)$ & $45(4.3)$ & $32(6.5)$ & $34(7.5)$ \\
\hline $18.5-24.9$ & $2434(72.3)$ & $293(60.2)$ & $607(68.9)$ & $799(76.2)$ & $379(76.9)$ & $356(78.1)$ \\
\hline $25-29.9$ & $526(15.6)$ & $109(22.4)$ & $167(19)$ & $137(13.1)$ & $63(12.8)$ & $50(11)$ \\
\hline $30+$ & $258(7.7)$ & $79(16.2)$ & $77(8.7)$ & $67(6.4)$ & $19(3.9)$ & $16(3.5)$ \\
\hline Maternal birth weight $(\mathrm{kg})^{\mathrm{a}}$ & $3.3 \pm(0.5)$ & $3.2 \pm(0.5)$ & $3.3 \pm(0.5)$ & $3.3 \pm(0.5)$ & $3.3 \pm(0.5)$ & $3.3 \pm 0.6$ \\
\hline$<2.50$ & $271(8.1)$ & $44(9)$ & $72(8.2)$ & $70(6.7)$ & $41(8.3)$ & $44(9.6)$ \\
\hline $2.50-3.9$ & $2735(81.3)$ & $403(82.8)$ & $704(79.9)$ & $861(82.2)$ & $405(82.2)$ & $362(79.4)$ \\
\hline$>4.0$ & $359(10.7)$ & $40(8.2)$ & $105(11.9)$ & $117(11.2)$ & $47(9.5)$ & $50(11)$ \\
\hline Polycystic ovary syndrome & $95(2.8)$ & $12(2.5)$ & $32(3.6)$ & $17(1.6)$ & $18(3.7)$ & $16(3.5)$ \\
\hline FH of hypertension & $1652(49.1)$ & $259(53.2)$ & $459(52.1)$ & $473(45.1)$ & $240(48.7)$ & $221(48.5)$ \\
\hline FH of diabetes & $488(14.5)$ & $86(17.7)$ & $126(14.3)$ & $149(14.2)$ & $63(12.8)$ & $64(14)$ \\
\hline Adult weight change, $\mathrm{kg}^{\mathrm{a}, \mathrm{b}}$ & $7.5 \pm 1.0$ & $9.9 \pm 12.6$ & $8.1 \pm 10.8$ & $6.8 \pm 9.3$ & $6.2 \pm 8.5$ & $6.5 \pm 7.7$ \\
\hline$<-2.5$ & $263(7.9)$ & $34(7.1)$ & $75(8.6)$ & $81(7.8)$ & $38(7.8)$ & $35(7.8)$ \\
\hline$-2.5-2.5$ & $773(23.3)$ & $92(19.3)$ & $197(22.7)$ & $260(25.2)$ & $126(25.9)$ & $98(21.9)$ \\
\hline $2.5-4.9$ & $553(16.7)$ & $73(15.3)$ & $138(15.9)$ & $165(16.0)$ & $101(20.7)$ & $76(17.0)$ \\
\hline $5.00-9.9$ & $776(23.4)$ & $91(19.1)$ & $180(20.7)$ & $263(25.5)$ & $106(21.8)$ & $136(30.4)$ \\
\hline$>10.0$ & $948(28.6)$ & $187(39.2)$ & $278(32.0)$ & $264(25.6)$ & $116(23.8)$ & $103(23.0)$ \\
\hline $\begin{array}{l}\text { Leisure time exercise during } \\
\text { pregnancy }\end{array}$ & $2933(87.2)$ & $434(89.1)$ & $758(86.0)$ & $920(87.8)$ & $428(86.8)$ & $393(86.2)$ \\
\hline History of infertility problem & $470(14.0)$ & $70(14.4)$ & $124(14.1)$ & $133(12.7)$ & $64(13.0)$ & $79(17.3)$ \\
\hline BMI 18 years $^{\mathrm{a}}$ & $20.6 \pm 2.9$ & $21.7 \pm 3.5$ & $20.9 \pm 2.8$ & $20.5 \pm 2.7$ & $20.1 \pm 2.6$ & $19.9 \pm 2.8$ \\
\hline$<18.5$ & $615(18.6)$ & $53(11.1)$ & $136(15.7)$ & $174(16.8)$ & $120(24.6)$ & $132(29.5)$ \\
\hline $18.5-24.9$ & $2493(75.2)$ & $367(76.8)$ & $678(78.2)$ & $804(77.7)$ & $347(71.3)$ & $297(66.3)$ \\
\hline $25.0-29.9$ & $157(4.7)$ & $39(8.2)$ & $41(4.7)$ & $45(4.3)$ & $16(3.3)$ & $16(3.6)$ \\
\hline$>30.0$ & $50(1.5)$ & $19(4.0)$ & $12(1.4)$ & $12(1.2)$ & $4(0.8)$ & $3(0.7)$ \\
\hline
\end{tabular}

${ }^{\text {a }}$ Mean (SD) otherwise $n(\%)$.

${ }^{b}$ Weight change from age 18 to pregnancy.

BMI: body mass index $\left(\mathrm{kg} / \mathrm{m}^{2}\right), \mathrm{FH}$ : family history.

$2.24-8.66)$. Women who gained $\geq 5.0 \mathrm{~kg}$ in adulthood and did not have long cycles or early menarche had 4- to 5 -fold higher risks of preeclampsia that were statistically significant compared with women who gained $<5 \mathrm{~kg}$ in adulthood and did not have long cycles (OR: 4.33, 95\% CI: 1.63-11.45) or early age at menarche (OR: 5.28, 95\% CI: $2.42-11.56)$, respectively ( $P$ values of interaction $>0.05$ ).

\section{Discussion}

We observed associations of early age at menarche with increased risk of preeclampsia and evidence of effect modification of the cycle length and risk of preeclampsia association by maternal prepregnancy body mass index. We also noted potential effect modifications of the early menarche and risk of preeclampsia association by maternal 
TABle 2: Association (odds ratio (OR), 95\% (CI)) between menstrual cycle characteristics and risk of preeclampsia.

\begin{tabular}{|c|c|c|c|c|c|c|c|c|}
\hline \multirow{2}{*}{ Characteristics } & \multirow{2}{*}{ Cases } & \multirow{2}{*}{ Noncases } & \multicolumn{2}{|c|}{ Unadjusted } & \multicolumn{2}{|c|}{ Adjusted Model 1} & \multicolumn{2}{|c|}{ Adjusted Model 2} \\
\hline & & & OR & $95 \%(\mathrm{CI})$ & OR & $95 \%(\mathrm{CI})$ & OR & $95 \%(\mathrm{CI})$ \\
\hline \multicolumn{9}{|c|}{ Usual menstrual cycle length (days) } \\
\hline $25-30$ & $55(68.8)$ & $2383(73.8)$ & 1.00 & Referent & 1.00 & Referent & 1.00 & Referent \\
\hline$<24$ & $4(5.0)$ & $148(4.6)$ & 1.17 & $0.42-3.27$ & 0.62 & $0.30-1.29$ & 0.72 & $0.34-1.49$ \\
\hline $31-35$ & $12(15.0)$ & 449 (13.9) & 1.16 & $0.61-2.18$ & 0.78 & $0.23-2.59$ & 0.88 & $0.26-3.00$ \\
\hline$\geq 36$ & $9(11.3)$ & $250(7.7)$ & 1.56 & $0.76-3.19$ & 0.74 & $0.31-1.80$ & 0.87 & $0.36-2.14$ \\
\hline \multicolumn{9}{|l|}{ Irregular menses } \\
\hline No & $67(83.8)$ & $2766(85.2)$ & 1.00 & Referent & 1.00 & Referent & 1.00 & Referent \\
\hline Yes & $13(16.3)$ & $482(14.8)$ & 0.89 & $(0.49-1.63)$ & 0.91 & $0.49-1.68$ & 1.01 & $0.54-1.90$ \\
\hline \multicolumn{9}{|c|}{ Age at menarche (years) } \\
\hline$\leq 11$ & $17(21.3)$ & $464(14.3)$ & 1.69 & $0.88-3.21$ & 1.77 & $0.92-3.38$ & 1.30 & $0.67-2.53 *$ \\
\hline 12 & $23(28.8)$ & $847(26.1)$ & 1.25 & $0.69-2.26$ & 1.29 & $0.71-2.34$ & 1.15 & $0.63-2.10^{*}$ \\
\hline 13 & $22(27.5)$ & $1015(31.3)$ & 1.00 & Referent & 1.00 & Referent & 1.00 & Referent* \\
\hline 14 & $10(12.5)$ & $480(14.8)$ & 0.96 & $0.45-2.04$ & 0.97 & $0.45-2.08$ & 1.01 & $0.47-2.18^{*}$ \\
\hline$\geq 15$ & $8(10.0)$ & $442(13.6)$ & 0.83 & $0.36-1.89$ & 0.83 & $0.36-1.90$ & 0.93 & $0.41-2.12 *$ \\
\hline
\end{tabular}

Model 1 is adjusted for maternal age, race/ethnicity, parity, maternal birth weight, and pregestational diabetes.

Model 2 includes additional adjustment for maternal prepregnancy body mass index.

*Trend $P$ value $<0.05$.

birth weight. Similarly, adult weight gain appeared to modify the associations of age at menarche with risk of preeclampsia and long menstrual cycles with risk of preeclampsia, though these interactions were not statistically significant.

Previously, early menarche ( $\leq 12$ years) has been associated with increased risk of CVD events [1]; investigators have hypothesized that observed associations are potentially mediated by increased adiposity associated with early menarche [1]. In the current study, we found an inverse relationship between age at menarche and increased risk of preeclampsia. In a case-control study, also conducted in Seattle, WA, Rudra and colleagues reported nonsignificant 3 -fold increase in risk of preeclampsia among overweight women with longer menstrual cycle length (OR: 3.11, 95\% CI: 0.62-15)[5], similar to our findings. The evidence from the current study is stronger since it is based on a study population from a prospective cohort study where maternal recall of age at menarche and menstrual characteristics is not influenced by the outcomes of the pregnancy. Previously, adult weight gain of $\geq 10 \mathrm{~kg}$ has also been associated with a 5-fold increased risk of preeclampsia (OR: 5.1, 95\% CI: 2.212.2) [25]. However, its role in the relationships of age at menarche and cycle length with risk of preeclampsia has not been well investigated. In the current study, we provide some evidence of potential synergistic interactions between these risk factors.

Girls who mature early (have early age at menarche) tend to be heavier (overweight or obese) as adults $[1,6$, 28]. It has been suggested that early maturing girls may have a longer period of positive energy balance or other endocrine factors that influence both the rate of sexual maturation and the accumulation of body fat [6]. Obesity is associated with cardiometabolic abnormalities, including inflammation, and oxidative stress insulin resistance, which have been related to preeclampsia and other pregnancy complications. A number of biomarkers (e.g., C-reactive protein, tumor necrosis alpha) or pathomechanisms (e.g., endothelial dysfunction and dyslipidemia) that have been shown to be associated with both overweight/obesity status and preeclampsia support this evidence $[4,9,16,19,28-30]$.

Birth weight is an indicator of intrauterine growth, a period of critical growth and programming [21-24]. Thus, maternal birth weight may be directly related to pathophysiologic changes that occur during pregnancy, including those that relate to risk of preeclampsia [21, 22]. In addition, maternal birth weight may play an indirect role in preeclampsia risk through its influence on other risk factors of preeclampsia (e.g., obesity).

Some limitations of our study deserve mention. While we collected and had access to information about maternal characteristics and other covariates, we are aware of the fact that self-reported medical histories may be subject to recall bias and misclassification. However, our prospective study design would assure that the potential misclassification is not conditional on the diagnosis of preeclampsia. Although we adjusted for several potential confounders, we cannot exclude the possibility of residual confounding. Finally, we cannot comment on the sequential influence of childhood and pubertal obesity on menstrual characteristics and eventual risk of preeclampsia.

\section{Conclusion}

We have shown that early onset of menarche is associated with an increased risk of preeclampsia and prepregnancy weight modifies associations of cycle length with risk of preeclampsia. Prepregnancy weight, adult weight gain, and maternal birth weight all appear to influence preeclampsia 
TABLE 3: Menstrual characteristics, age at menarche, body weight measurements, and the risk of preeclampsia.

\begin{tabular}{|c|c|c|c|c|c|c|}
\hline \multirow{2}{*}{ Stratifying covariates and exposure of interest } & \multirow{2}{*}{ Cases } & \multirow{2}{*}{ Noncases } & \multicolumn{2}{|c|}{ Stratified by BMI } & \multicolumn{2}{|c|}{ Joint models } \\
\hline & & & Adj. OR & $95 \%(\mathrm{CI})$ & Adj. OR & $95 \%(\mathrm{CI})$ \\
\hline \multicolumn{7}{|l|}{ Prepregnancy BMI and long cycle length ${ }^{1}$} \\
\hline$<25 \mathrm{~kg} / \mathrm{m}^{2},<36$ days & $35(43.8)$ & $2327(71.6)$ & 1.00 & Referent & 1.00 & Referent \\
\hline$<25 \mathrm{~kg} / \mathrm{m}^{2}, \geq 36$ days & $7(8.8)$ & $187(5.8)$ & 2.56 & $1.12-5.88$ & 2.50 & $1.09-5.72$ \\
\hline$\geq 25 \mathrm{~kg} / \mathrm{m}^{2},<36$ days & $36(45.0)$ & $653(20.1)$ & 1.00 & Referent & 3.78 & $2.35-6.08$ \\
\hline$\geq 25 \mathrm{~kg} / \mathrm{m}^{2}, \geq 36$ days & $2(2.5)$ & $81(2.5)$ & 0.44 & $0.10-1.84$ & 1.67 & $0.40-7.09$ \\
\hline \multicolumn{7}{|l|}{ Prepregnancy BMI and early age at menarche } \\
\hline$<25 \mathrm{~kg} / \mathrm{m}^{2},>11$ years & $37(46.3)$ & $2223(68.4)$ & 1.00 & Referent & Referent & Referent \\
\hline$<25 \mathrm{~kg} / \mathrm{m}^{2}, \leq 11$ years & $5(6.3)$ & $291(9.0)$ & 1.13 & $0.44-2.92$ & 1.08 & $0.42-2.76$ \\
\hline$\geq 25 \mathrm{~kg} / \mathrm{m}^{2},>11$ years & $26(32.5)$ & $561(17.3)$ & 1.00 & Referent & 2.86 & $1.71-4.77$ \\
\hline$\geq 25 \mathrm{~kg} / \mathrm{m}^{2}, \leq 11$ years & $12(15.0)$ & $173(5.3)$ & 1.48 & $0.72-3.02$ & 4.41 & $2.24-8.66$ \\
\hline \multicolumn{7}{|l|}{ Maternal birth weight and long cycle length } \\
\hline$\geq 2500$ gr,$<36$ days & $64(80.0)$ & $2755(84.8)$ & 1.00 & Referent & Referent & Referent \\
\hline$\geq 2500$ gr, $\geq 36$ days & $7(8.8)$ & $225(6.9)$ & 1.36 & $0.61-3.00$ & 1.36 & $0.31-3.00$ \\
\hline$<2500$ gr, $<36$ days & $2(2.5)$ & $33(1.0)$ & 1.00 & Referent & 2.65 & $0.62-11.31$ \\
\hline$<2500$ gr, $\geq 36$ days & $7(8.8)$ & $235(7.2)$ & 0.53 & $0.10-2.84$ & 1.28 & $0.58-2.83$ \\
\hline \multicolumn{7}{|l|}{ Maternal birth weight and early age at menarche } \\
\hline$\geq 2500$ gr, $>11$ years & $57(71.3)$ & $2566(79.0)$ & 1.00 & Referent & Referent & Referent \\
\hline$\geq 2500$ gr, $\leq 11$ years & $3(3.8)$ & $40(1.2)$ & 3.57 & $1.06-11.96$ & 3.57 & $1.07-11.93$ \\
\hline$<2500 \mathrm{gr},>11$ years & $6(7.5)$ & $218(6.7)$ & 1.00 & Referent & 1.26 & $0.54-2.95$ \\
\hline$<2500 \mathrm{gr}, \leq 11$ years & $14(17.5)$ & $424(13.1)$ & 1.20 & $0.45-3.18$ & 1.54 & $0.85-2.80$ \\
\hline \multicolumn{7}{|l|}{ Adult weight gain ${ }^{2}$ and long usual cycle length } \\
\hline$<5.0 \mathrm{~kg},<36$ days & $14(17.5)$ & $1441(44.4)$ & 1.00 & Referent & Referent & Referent \\
\hline$<5.0 \mathrm{~kg}, \geq 36$ days & $3(3.8)$ & $122(3.8)$ & 2.71 & $0.76-9.72$ & 2.47 & $0.70-8.73$ \\
\hline$\geq 5.0 \mathrm{~kg},<36$ days & $57(71.3)$ & $1539(47.4)$ & 1.00 & Referent & 3.87 & $2.14-6.98$ \\
\hline$\geq 5.0 \mathrm{~kg}, \geq 36$ days & $6(7.5)$ & $146(4.5)$ & 1.12 & $0.47-2.64$ & 4.33 & $1.63-11.45$ \\
\hline \multicolumn{7}{|l|}{ Adult weight gain and early age at menarche } \\
\hline$<5.0 \mathrm{~kg},>11$ years & $13(16.3)$ & $1369(42.2)$ & 1.00 & Referent & Referent & Referent \\
\hline$<5.0 \mathrm{~kg}, \leq 11$ years & $4(5.0)$ & $194(6.0)$ & 2.40 & $0.77-7.52$ & 2.26 & $0.73-7.03$ \\
\hline$\geq 5.0 \mathrm{~kg},>11$ years & $50(62.5)$ & $1415(43.6)$ & 1.00 & Referent & 3.79 & $2.05-7.03$ \\
\hline$\geq 5.0 \mathrm{~kg}, \leq 11$ years & $13(16.3)$ & $270(8.3)$ & 1.36 & $0.47-2.64$ & 5.28 & $2.41-11.56$ \\
\hline
\end{tabular}

All models are adjusted for age, race, family history of diabetes, and physical activity.

${ }^{1}$ Interaction $P$ value 0.04 .

${ }^{2}$ Adult weight gain: difference between weight at age 18 and prepregnancy weight.

risk associated with early age at menarche and longer menstrual cycles. Future larger studies that investigate this research area may create opportunities for prevention and early intervention of preeclampsia.

\section{Acknowledgments}

The authors wish to thank the staff of the Center for Perinatal Studies, Swedish Medical Center, Seattle, WA, USA, for their technical assistance with this research. This research was supported by awards from the National Institutes of Health (R01HD-055566 and R01HD-32562).

\section{References}

[1] R. Lakshman, N. G. Forouhi, S. J. Sharp et al., "Early age at menarche associated with cardiovascular disease and mortality," Journal of Clinical Endocrinology and Metabolism, vol. 94, no. 12, pp. 4953-4960, 2009.

[2] J. Chavarro, E. Villamor, J. Narváez, and A. Hoyos, "Sociodemographic predictors of age at menarche in a group of Colombian university women," Annals of Human Biology, vol. 31, no. 2, pp. 245-257, 2004.

[3] M. A. De Leciñana, J. A. Egido, C. Fernández et al., "Risk of ischemic stroke and lifetime estrogen exposure," Neurology, vol. 68, no. 1, pp. 33-38, 2007. 
[4] M. J. De Vries, G. A. Dekker, and J. Schoemaker, "Higher risk of preeclampsia in the polycystic ovary syndrome: a case control study," European Journal of Obstetrics Gynecology and Reproductive Biology, vol. 76, no. 1, pp. 91-95, 1998.

[5] C. L. Rudra and M. A. Williams, "BMI as a modifying factor in the relations between age at menarche, menstrual cycle characteristics, and risk of preeclampsia," Gynecological Endocrinology, vol. 21, no. 4, pp. 200-205, 2005.

[6] D. S. Freedman, L. K. Khan, M. K. Serdula, W. H. Dietz, S. R. Srinivasan, and G. S. Berenson, "The relation of menarcheal age to obesity in childhood and adulthood: the Bogalusa heart study," BMC Pediatrics, vol. 3, no. 1, article 3, p. 3, 2003.

[7] C. G. Solomon, F. B. Hu, A. Dunaif et al., "Menstrual cycle irregularity and risk for future cardiovascular disease," Journal of Clinical Endocrinology and Metabolism, vol. 87, no. 5, pp. 2013-2017, 2002.

[8] S. M. Veltman-Verhulst, B. B. van Rijn, H. E. Westerveld et al., "Polycystic ovary syndrome and early-onset preeclampsia: reproductive manifestations of increased cardiovascular risk," Menopause, vol. 17, no. 5, pp. 990-996, 2010.

[9] D. A. Enquobahrie, M. A. Williams, C. L. Butler, I. O. Frederick, R. S. Miller, and D. A. Luthy, "Maternal plasma lipid concentrations in early pregnancy and risk of preeclampsia," American Journal of Hypertension, vol. 17, no. 7, pp. 574-581, 2004.

[10] B. Huppertz, "Placental origins of preeclampsia: challenging the current hypothesis," Hypertension, vol. 51, no. 4, pp. 970975, 2008.

[11] S. Grill, C. Rusterholz, R. Zanetti-Dällenbach et al., "Potential markers of preeclampsia," Reproductive Biology and Endocrinology, vol. 7, article no. 70, 2009.

[12] J. R. Barton and B. M. Sibai, "Prediction and prevention of recurrent preeclampsia," Obstetrics and Gynecology, vol. 112, no. 2, pp. 359-372, 2008.

[13] M. Muy-Rivera, S. Vadachkoria, G. B. Woelk, C. Qiu, K. Mahomed, and M. A. Williams, "Maternal plasma VEGF, sVEGF$\mathrm{R} 1$, and PlGF concentrations in preeclamptic and normotensive pregnant Zimbabwean women," Physiological Research, vol. 54, no. 6, pp. 611-622, 2005.

[14] D. A. Enquobahrie, M. A. Williams, C. Qiu, G. B. Woelk, and K. Mahomed, "Maternal plasma transforming growth factor$\beta 1$ concentrations in preeclamptic and normotensive pregnant Zimbabwean women," Journal of Maternal-Fetal and Neonatal Medicine, vol. 17, no. 5, pp. 343-348, 2005.

[15] T. E. O’Brien, J. G. Ray, and W. S. Chan, "Maternal body mass index and the risk of preeclampsia: a systematic overview," Epidemiology, vol. 14, no. 3, pp. 368-374, 2003.

[16] M. H. Aliyu, S. Luke, S. Kristensen, A. P. Alio, and H. M. Salihu, "Joint effect of obesity and teenage pregnancy on the risk of preeclampsia: a population-based study," Journal of Adolescent Health, vol. 46, no. 1, pp. 77-82, 2010.

[17] I. A. Siddiqui, A. Jaleel, W. Tamimi, and H. M. F. Al Kadri, "Role of oxidative stress in the pathogenesis of preeclampsia," Archives of Gynecology and Obstetrics, vol. 282, no. 5, pp. 469474, 2010.

[18] A. Barden, R. Singh, B. N. Walters, J. Ritchie, B. Roberman, and L. J. Beilin, "Factors predisposing to pre-eclampsia in women with gestational diabetes," Journal of Hypertension, vol. 22, no. 12, pp. 2371-2378, 2004.

[19] S. E. Sanchez, C. Zhang, M. A. Williams et al., "Tumor necrosis factor- $\alpha$ soluble receptor p55 (sTNFp55) and risk of preeclampsia in Peruvian women," Journal of Reproductive Immunology, vol. 47, no. 1, pp. 49-63, 2000.
[20] M. A. Williams, K. Mahomed, A. Farrand et al., "Plasma tumor necrosis factor- $\alpha$ soluble receptor p55 (sTNFp55) concentrations in eclamptic, preeclamptic and normotensive pregnant Zimbabwean women," Journal of Reproductive Immunology, vol. 40, no. 2, pp. 159-173, 1998.

[21] M. A. Williams, I. Emanuel, C. Kimpo, W. M. Leisenring, and C. B. Hale, "A population-based cohort study of the relation between maternal birthweight and risk of gestational diabetes mellitus in four racial/ethnic groups," Paediatric and Perinatal Epidemiology, vol. 13, no. 4, pp. 452-465, 1999.

[22] J. C. Dempsey, M. A. Williams, D. A. Luthy, I. Emanuel, and K. Shy, "Weight at birth and subsequent risk of preeclampsia as an adult," American Journal of Obstetrics and Gynecology, vol. 189, no. 2, pp. 494-500, 2003.

[23] I. Emanuel, W. Leisenring, M. A. Williams et al., "The Washington State intergenerational study of birth outcomes: methodology and some comparisons of maternal birthweight and infant birthweight and gestation in four ethnic groups," Paediatric and Perinatal Epidemiology, vol. 13, no. 3, pp. 352369, 1999.

[24] T. P. Strandjord, I. Emanuel, M. A. Williams, W. M. Leisenring, and C. Kimpo, "Respiratory distress syndrome and maternal birth weight effects," Obstetrics and Gynecology, vol. 95, no. 2, pp. 174-179, 2000.

[25] I. O. Frederick, C. B. Rudra, R. S. Miller, J. C. Foster, and M. A. Williams, "Adult weight change, weight cycling, and prepregnancy obesity in relation to risk of preeclampsia," Epidemiology, vol. 17, no. 4, pp. 428-434, 2006.

[26] E. J. Roccella, "Report of the national high blood pressure education program working group on high blood pressure in pregnancy," American Journal of Obstetrics and Gynecology, vol. 183, no. 1, pp. S1-S22, 2000.

[27] K. J. Rothman, S. Greenland, and T. L. Lash, Modern Epidemiology, Lippincott Williams \& Wilkins, Philadelphia, Pa, USA, 3rd edition, 2008.

[28] M. B. Pierce and D. A. Leon, "Age at menarche and adult BMI in the Aberdeen Children of the 1950s Cohort Study," American Journal of Clinical Nutrition, vol. 82, no. 4, pp. 733739, 2005.

[29] R. M. Mazar, S. K. Srinivas, M. D. Sammel, C. M. Andrela, and M. A. Elovitz, "Metabolic score as a novel approach to assessing preeclampsia risk," American Journal of Obstetrics and Gynecology, vol. 197, no. 4, pp. 411-e1-411-e5, 2007.

[30] C. Qiu, D. A. Luthy, C. Zhang, S. W. Walsh, W. M. Leisenring, and M. A. Williams, "A prospective study of maternal serum C-reactive protein concentrations and risk of preeclampsia," American Journal of Hypertension, vol. 17, no. 2, pp. 154-160, 2004. 


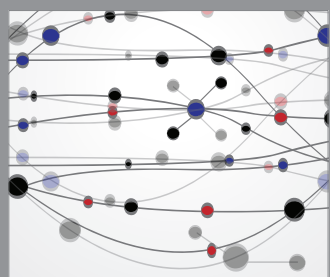

The Scientific World Journal
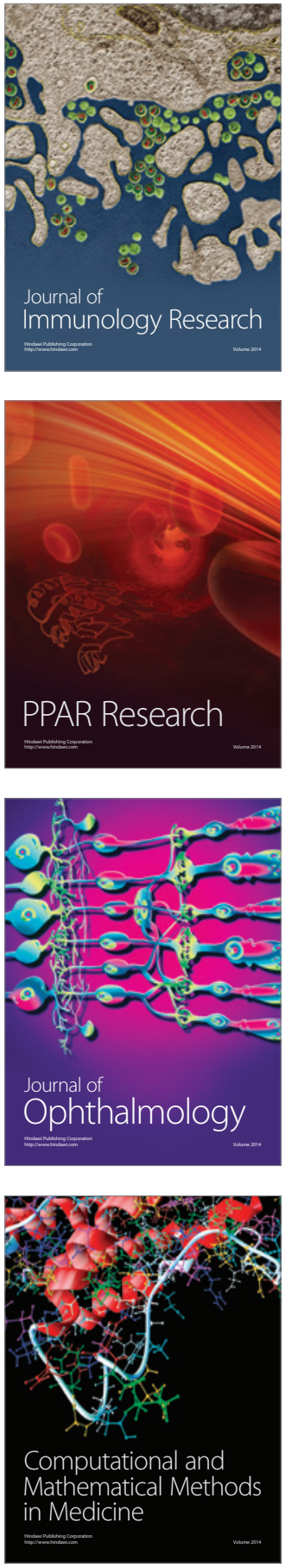

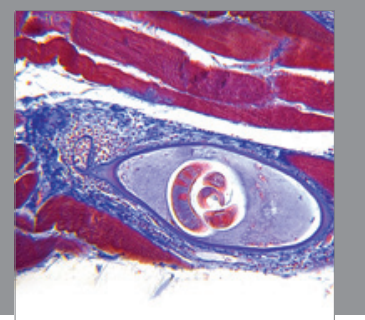

Gastroenterology

Research and Practice
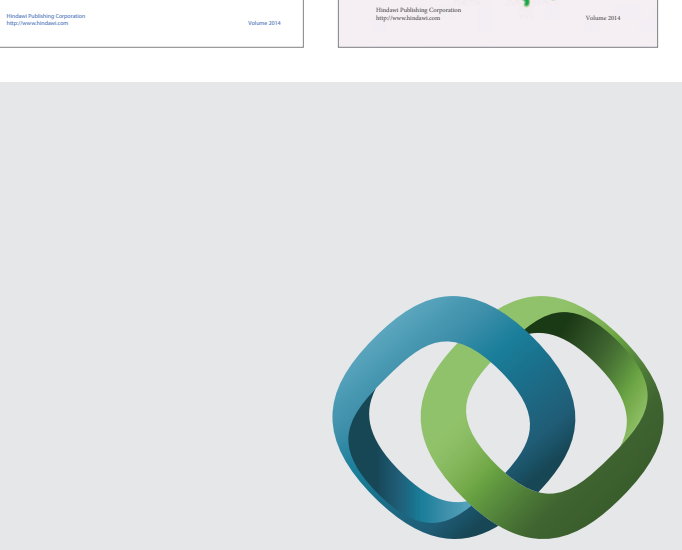

\section{Hindawi}

Submit your manuscripts at

http://www.hindawi.com
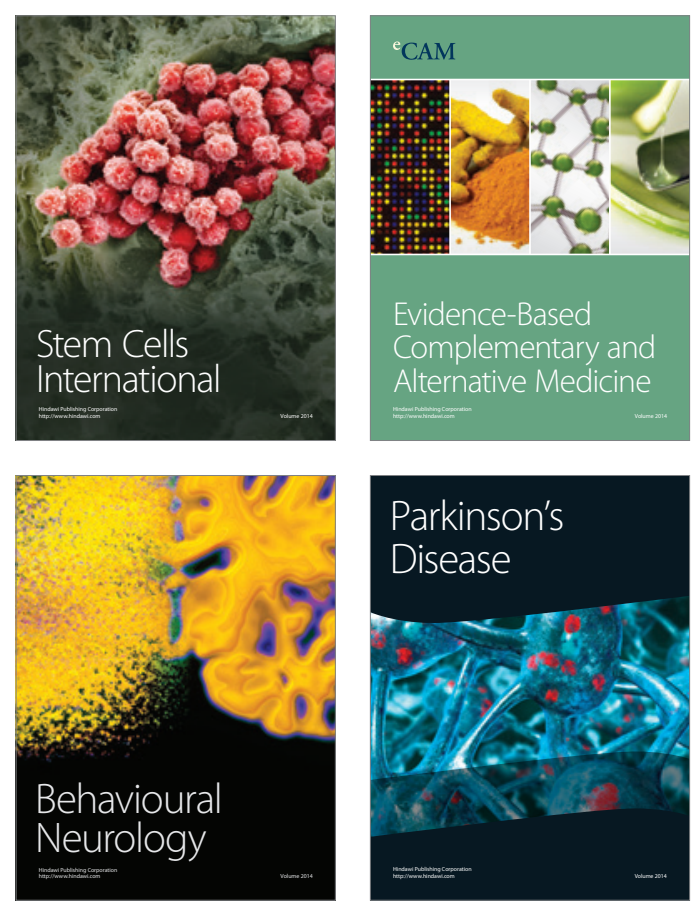

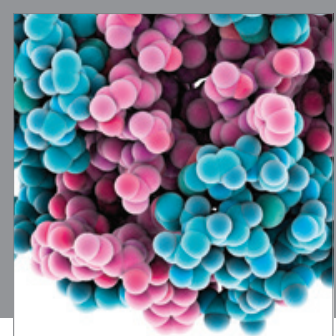

Journal of
Diabetes Research

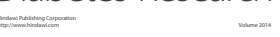

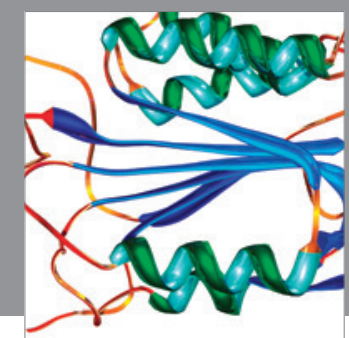

Disease Markers
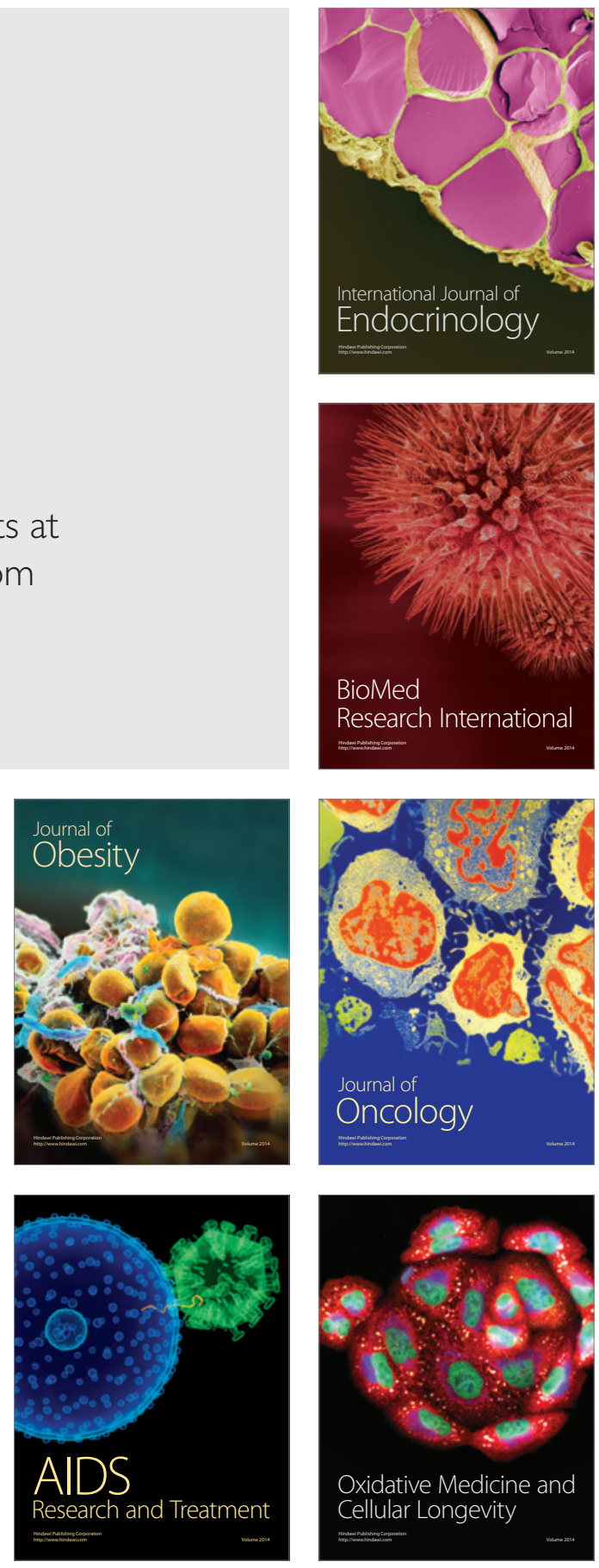